\title{
LEGISLAÇÃO AMBIENTAL APLICÁVEL À POLUIÇÃO SONORA URBANA: UM ESTUDO DAS NORMAS E DIRETRIZES DISCIPLINARES
}

\author{
ENVIRONMENTAL LAW APPLICABLE TO URBAN \\ NOISE POLLUTION: A STUDY ON THE STANDARDS \\ AND DISCIPLINERY DIRECTIVES
}

\section{Bressane, A. ${ }^{1}$, Mochizuki, P. S. ${ }^{2}$, Gobbi, N. ${ }^{3}$, Carvalho, M. D. ${ }^{4}$ \\ ${ }^{1}$ Mestrando em Engenharia Urbana / UFSCar, ab_engamb@yahoo.com.br, ${ }^{2}$ Engenheira Ambiental / UNESP, patriciasatye@yahoo.com.br, ${ }^{3}$ Bacharel em Direito, Livre-docente / UNESP, ngobbi@rc.unesp.br, ${ }^{4}$ Bacharel em Direito, advogado / FADISC, dinizcasagrande@hotmail.com}

\section{RESUMO}

Diante da crescente degradação dos cenários urbanos vem se destacando a Poluição Sonora, discutida nesse estudo no contexto da Legislação Federal aplicável, visando contribuir com a atuação de gestores que buscam restabelecer a qualidade de vida comprometida pelo ruído e, sobretudo, objetivam prevenir suas cidades contra esse problema. Como resultado, foi reunido um amplo e abrangente conjunto de soluções legislativas contemplando as principais causas de conflitos sonoros urbanos. Palavras chave: Poluição sonora, Legislação ambiental e Gestão urbana.

\section{ABSTRACT}

A factor contributing to increasing urban degradation is noise pollution, discussed on this study in relation to the applicable Federal Brazilian legislation with the aim of contributing to inform the actions of decision makers who seek to recover quality of life that has been compromised by noise and protect their cities from this problem. The result is a compilation of solutions for the principal causes of urban noise conflicts.

Keywords: Noise pollution, Environmental law and Urban management. 


\section{INTRODUÇÃO}

Atualmente, no contexto urbano trava-se confronto com uma das principais formas de agressão que contamina intensamente as relações sociais, a Poluição Sonora. Herança de um acentuado crescimento, muitas vezes sob a carência de um planejamento adequado, a poluição sonora vem sendo considerada uma das maiores preocupações da sociedade moderna segundo a Organização Mundial da Saúde (OMS, 2003) e questão de saúde pública desde o Congresso Mundial sobre Poluição Sonora em 1989, na Suécia (FERNANDES, 2002).

Nesse sentido, a falta de controle acústico em ambientes ruidosos nos reporta claramente ao conceito de poluição definido pela Política Nacional do Meio Ambiente - PNMA, Lei Federal $\mathbf{n}^{\mathbf{0}} \mathbf{6 . 9 3 8} / \mathbf{1 9 8 1}$ (BRASIL, 1981), quando a emissão sonora extrapola os padrões ambientais estabelecidos, prejudicando a saúde, a segurança e o bem estar da população.

Assim, a negligência quanto à poluição sonora está sob pena de comprometer a qualidade de vida urbana, o que tem provocado o despertar da consciência ecológica e a atenção da cultura jurídica contemporânea, visando coibir atividades e/ou condutas lesivas a terceiros e ao meio ambiente.

Para isso, a legislação representa um instrumento disciplinar com fins de prevenção e controle, dispondo sobre padrões, normas e diretrizes capazes de orientar a atuação dos diversos agentes envolvidos, como será discutido ao longo desse estudo.

\section{OBJETIVO E JUSTIFICATIVA}

A legislação brasileira, de um modo geral, vem sendo elaborada de forma fragmentária, muitas vezes em prejuízo da necessária coerência e harmonia, sem um trabalho mais criterioso de compatibilização dos diferentes diplomas legais, o que dificulta o tratamento sistemático de matérias importantes, bem como sua compreensão e aplicabilidade (ANDRADA, 1997). Segundo Troppmair (2002): “[...] em nosso país a legislação referente à poluição sonora é muito elástica e vaga".

Em consonância com Machado (2005): "Não basta que temporalmente existam normas, mas a qualidade dessas exigências tem que evitar, com adequada margem de segurança, os danos da poluição sonora".

Com isso, verifica-se a necessidade de reunir os dispositivos legais aplicáveis à poluição sonora, abordando-os de forma sistêmica, pois, embora vasta, e considerada uma das mais avançadas e completas do mundo, a aplicabilidade da legislação brasileira também se prejudica, em especial, porque ocorrem temas novos com grande freqüência no cenário ambiental, fazendo com que grande parte da população, $\mathrm{e}$ até mesmo o próprio poder público, desconheça seus direitos e deveres (PINHEIRO-PEDRO, 2005). 
Logo, ao discutir de forma ampla e abrangente os diversos dispositivos legais aplicáveis à poluição sonora, esse estudo visa contribuir para uma efetiva atuação de gestores que buscam restabelecer a qualidade de vida comprometida pelo ruído urbano em seu município e, sobretudo, objetivam prevenir-se contra esse problema.

\section{MATERIAIS E MÉTODOS}

Por se tratar de uma pesquisa bibliográfica, para o desenvolvimento do presente estudo os materiais utilizados consistem em pesquisas acadêmicas correlatas ao tema poluição sonora urbana e, sobretudo, doutrinas e dispositivos legais aplicáveis.

Concentrando-se no âmbito federal, destaque deve ser atribuído ao levantamento documental realizado através de consultas às bases digitais oficiais de legislação disponibilizados pelo Governo, representadas pelas bases online da presidência e do Conselho Nacional do Meio Ambiente - CONAMA, por reunirem todo conjunto de normas de interesse aos propósitos desse estudo.

$\mathrm{O}$ acesso às fontes de consulta e as etapas de seleção e análise dos materiais levantados foram desenvolvidas mediante planos de pesquisa e leitura baseados em um fichário bibliográfico formulado para este fim.

A definição de palavras-chaves durante o levantamento de materiais foi fundamental para garantir a abordagem dos principais dispositivos legais aplicáveis, entre elas: "ruído", "poluição sonora" e "legislação". Dessa forma, os resultados obtidos com tais procedimentos subsidiaram o embasamento cognitivo necessário à elaboração do trabalho em suas diferentes partes, adiante apresentadas.

\section{RESULTADOS}

Segundo Milaré (2001):

A legislação não tem se estendido muito a respeito do ruído como elemento perturbador da qualidade ambiental. O que se deve, provavelmente ao fato de não haver tanta complexidade técnica, administrativa e legal no controle da chamada Poluição Sonora.

Todavia, responder a essa colocação requer fundamentalmente a abordagem pretendida com esse estudo, no qual segue oportuna discussão a esse respeito.

\subsection{Em Caráter Geral: Desenvolvimento Urbano e Qualidade de Vida}

Em caráter geral, o tema poluição sonora urbana pode ser logo introduzido pelo art. 182 da Constituição Federal Brasileira vigente (BRASIL, 1988), ao apresentar entre os dispositivos da política urbana, o objetivo de ordenar plenamente o desenvolvimento das funções sociais da cidade e garantir o bem-estar de seus 
habitantes, reforçado pelo art. 225 do mesmo diploma:

Art. 225. Todos têm direito ao meio ambiente ecologicamente equilibrado, bem de uso comum do povo e essencial à sadia qualidade de vida, [...].

Em consonância, no rol dos objetivos de seu art.4 $4^{\circ}$, a Política Nacional do Meio Ambiente, Lei Federal $\mathbf{n}^{\mathbf{0}}$. 6.938/1981, preceitua a compatibilização do desenvolvimento socioeconômico com a preservação da qualidade ambiental e do equilíbrio ecológico.

Ao tratarmos das resoluções CONAMA $\mathrm{n}^{\circ}$. 001/1990 (BRASIL, 1990a), CONAMA $n^{\circ}$. 002/1990 (BRASIL, 1990b) e CONAMA nº. 020/1994 (BRASIL, 1994), passamos ao tema Poluição Sonora de forma mais específica, apresentando três dos principais dispositivos legais que versam a respeito. A Resolução CONAMA no . 001/1990 dispõe sobre a emissão de ruídos, em decorrência de quaisquer atividades industriais, comerciais, sociais ou recreativas, determinando padrões, critérios e diretrizes.

Nessa resolução são indicadas as normas da Associação Brasileira de Normas Técnicas (ABNT): NBR no. 10.151 (ABNT, 2000) - Avaliação do Ruído em Áreas Habitadas visando o conforto da comunidade - originalmente de 1987, atualmente em vigor após revisão no ano de 2000, mas retificada pela Errata NBR no $\mathbf{1 0 . 1 5 1}$ (ABNT, 2003); e a norma técnica NBR no $\mathbf{1 0 . 1 5 2}$ (ABNT, 1987) - Avaliação do Ruído em Áreas Habitadas visando o conforto acústico - as quais devem ser observadas quanto ao controle dos níveis sonoros e, na execução dos projetos de construção ou de reformas de edificações para atividades heterogêneas, respectivamente. Entre estas ainda deve ser lembrada a norma técnica NBR no. 7.731 (ABNT, 1983) - Guia para execução de serviços de medição de ruído aéreo e avaliação de seus efeitos sobre o homem - uma das principais normas brasileiras sobre acústica que define aspectos fundamentais sobre os procedimentos associados.

A Resolução CONAMA no . 002/1990 institui em caráter nacional o Programa Silêncio, visando controlar o ruído excessivo que possa interferir na saúde e bemestar da população. Sob a coordenação do Instituto Brasileiro do Meio Ambiente e Recursos Naturais Renováveis (IBAMA), essa resolução prevê o estabelecimento de convênios, contratos e atividades afins com órgãos e entidades que, direta ou indiretamente, possam contribuir para o desenvolvimento deste Programa.

Por fim, a Resolução CONAMA no. 020/1994 institui o Selo Ruído, obrigatório para aparelhos eletrodomésticos que gerem ruído em seu funcionamento, como forma de indicação do seu nível de potência sonora. Nesta resolução, atribui-se ao fabricante ou representante legal a responsabilidade pela realização de ensaios e solicitação ao IBAMA para obtenção deste selo.

Em caráter geral, dada a crescente importância que a temática vem adquirindo em todo o mundo, a constituição brasileira vigente deu um admirável passo na busca por um desenvolvimento sustentável, mais uma vez se destacando no cenário internacional com o advento do disposto no art. 225. Com isso, reforçou os 
propósitos da Política Nacional do Meio Ambiente no combate à poluição, legitimando o poder público local a atuar no tratamento de problemas ambientais urbanos, tal como é o caso da poluição sonora.

As demais leis, resoluções e, sobretudo, as normas técnicas apresentadas também têm respaldado o procedimento de diversas pesquisas em áreas acusticamente degradadas, viabilizando tanto o mapeamento de níveis sonoros (avaliações objetivas) como a identificação dos respectivos efeitos sobre as comunidades afetadas através de estudos da percepção ao ruído ambiental (avaliações subjetivas).

Logo, além de amparar os gestores públicos e agentes privados, diretamente através de seus preceitos e, indiretamente através destes e outros estudos viabilizados pelos dispositivos legais apresentados, verifica-se a necessidade de implementação de medidas administrativas e legais complementares às diretrizes federais discutidas, subsidiando o controle e a prevenção do ruído no contexto municipal.

Visando combater a poluição sonora urbana, tais leis complementares, sobretudo, embasadas nas próprias diretrizes federais, devem compor a Política Municipal do Meio Ambiente que poderá contar com diversos instrumentos de implementação, tais como: Lei do Plano Diretor, Lei de Uso, Parcelamento e Ocupação do Solo Urbano, Código de Obras, Código de Posturas, Código Ambiental ou, até mesmo, uma lei específica para o tema sonoro, entre outros (SÃO PAULO, 1992).

As decisões que envolvem a implantação dos instrumentos acima citados requerem avaliar quais são os mais apropriados a cada peculiaridade, evidenciando a importância de conhecer a tutela jurídica federal existente, cuja discussão segue adiante sobre os principais fatores relacionados.

\subsection{Propriedade, Uso e Ocupação do Espaço Urbano}

Em seu inciso VIII do art. 30, a Constituição Federal Brasileira relaciona entre as competências atribuídas aos municípios promover, no que couber, adequado ordenamento territorial, mediante planejamento e controle do uso, do parcelamento e da ocupação do solo urbano.

Nesse sentido, mesmo anterior a Constituição vigente, já dispúnhamos da Lei Federal $\mathbf{n}^{\mathbf{0}} \mathbf{. 6 . 8 0 3 / 1 9 8 0}$ (BRASIL, 1980) que estabelece, em seu art.9º a destinação de zonas para instalações industriais mediante zoneamento urbano, considerando, entre as características do processo de produção, a vibração mecânica e a emissão de ruídos.

Visando a compatibilização de desenvolvimento econômico e social com a preservação da qualidade ambiental e do equilíbrio ecológico, a Lei Federal $\mathbf{n}^{\mathbf{0}}$. 6.938/ 1981, no art. $9^{\circ}$, estabelece como seus instrumentos de atuação o próprio zoneamento, a avaliação de impactos ambientais e o licenciamento de atividades potencialmente poluidoras, entre elas, as ruidosas.

Regulamentando o previsto neste artigo, art. $9^{\circ}$ da Lei 6.938/1981, a Resolução 
CONAMA no ${ }^{0}$ 001/1986 (BRASIL, 1986) dispõe sobre a execução e elaboração do Estudo de Impacto Ambiental e Relatório de Impacto ao Meio Ambiente, como instrumentos da Política Nacional do Meio Ambiente - PNMA. Por sua vez, a utilização do sistema de licenciamento como instrumento de gestão ambiental, instituído pela PNMA, é regulamentada pela Resolução CONAMA nº 237/1997 (BRASIL, 1997).

Nesse contexto, a Lei Federal $\mathbf{n}^{\mathbf{0}} \mathbf{1 0 . 2 5 7 / 2 0 0 1}$ (BRASIL, 2001), denominada Estatuto da Cidade, estabelece diretrizes gerais para a política de desenvolvimento urbano, sobre a qual versam os artigos 182 e 183 da Constituição Federal de 1988. Para isso, dispõe sobre normas de ordem pública e interesse social que regulam o uso da propriedade urbana em prol do bem coletivo, tal como do equilíbrio ambiental, da segurança e do bem-estar dos cidadãos.

Como preceitua a Lei Federal $n^{\circ}$. 6.938/1981, o art. $4^{\circ}$ do Estatuto da Cidade estabelece o planejamento municipal entre os instrumentos da política urbana, em especial, o Plano Diretor, a disciplina do parcelamento, do uso e da ocupação do solo, o zoneamento ambiental, o estudo de impacto ambiental (EIA) e o estudo prévio de impacto de vizinhança.

No que tange à Poluição Sonora proveniente do mau uso da propriedade e ordenamento territorial inadequado, embora não desobrigue o EIA, um dos dispositivos de suma relevância introduzido por esta lei é o, supracitado, Estudo de Impacto de Vizinhança (EIV), para obtenção de licenças ou autorizações de construção, ampliação ou operação, de empreendimentos previamente definidos por Lei Municipal.

O Estatuto da Cidade, Lei Federal $n^{\circ}$. 10.257/2001, ainda define o cumprimento da função social da propriedade urbana como o atendimento das exigências fundamentais de ordenação da cidade, o que se aplica ao controle da Poluição Sonora, tal como deve ser expresso pelo Plano Diretor municipal, sendo este obrigatório para cidades com mais de vinte mil habitantes, integrantes de regiões metropolitanas, aglomerações urbanas e etc.

Nesse sentido, a Lei Federal $\mathbf{n}^{\mathbf{0}} \mathbf{. 1 0 . 4 0 6 / 2 0 0 2}$ (BRASIL, 2002), que institui o novo Código Civil Brasileiro, traz no escopo de seus dispositivos, arts. 1277, 1278 e 1279 , os direitos de vizinhança quanto ao uso anormal da propriedade, assegurando o direito à saúde, sossego e segurança, mediante o controle das atividades nocivas, considerando-se a natureza da utilização, a localização do estabelecimento, as normas que distribuem as edificações em zonas e os limites ordinários de tolerância dos moradores da vizinhança.

Entretanto, controle não significa necessariamente supressão da causa, mas sim manipulação do efeito (FERNANDES, 2002). Em consonância, o Código Civil esclarece que a perturbação, quando justificada por interesse público, pode não ser cerceada, mas, contudo, pode gerar ao proprietário ou possuidor, causador dela, o ônus do pagamento de indenização cabal, não descartando, ainda, a redução ou eliminação do incômodo que podem ser exigidas quando possíveis. 
Nesse contexto, o conjunto de fatores associados ao adequado ordenamento territorial, bem como à função social da propriedade, tem como amparo os dispositivos acima apresentados que, na ausência de leis municipais específicas, destacam-se como instrumentos fundamentais para a gestão urbana, já que visam um equilibrado plano de desenvolvimento, contribuindo para o controle da poluição sonora local.

Dessa forma, tais instrumentos legais e normativos, e ainda, os resultados proporcionados pelos diversos estudos apoiados por tais dispositivos, podem contribuir fundamentalmente para o planejamento ambiental urbano no que se refere à poluição sonora, auxiliando a proposição de diretrizes gerais capazes de orientar o ordenamento do espaço urbano através da compatibilização de sua configuração e estruturas componentes com suas respectivas funções definidas pelo zoneamento urbano, além de embasar leis complementares.

\subsection{Trânsito de Veículos Automotores e Tráfego Aéreo}

Segundo a Resolução CONAMA no. 001/1990, as emissões de ruídos produzidos por veículos automotores devem obedecer às normas expedidas pelo Conselho Nacional de Trânsito.

Todavia, o Código Brasileiro de Trânsito, instituído pela Lei no. 9.503/1997 (BRASIL, 1997), determina que os veículos em circulação tenham o controle de emissão de ruídos avaliado mediante inspeção, que será obrigatória, na forma e periodicidade estabelecidas pelo Conselho Nacional do Meio Ambiente, talvez porque mesmo anteriores a Lei 9.503/1997, seguem inúmeras resoluções emitidas pelo próprio CONAMA quanto aos níveis emissivos de ruído veicular.

Nesse contexto, os limites máximos de ruído com o veículo em aceleração e na condição parado são estabelecidos pela Resolução CONAMA n $^{0}$. 001/1993 (BRASIL, 1993a), para os veículos nacionais e importados, exceto motocicletas, motonetas, ciclomotores, bicicletas com motor auxiliar e veículos assemelhados que,

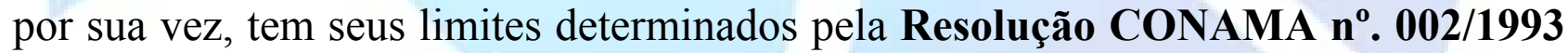
(BRASIL, 1993b).

Para isso, tais resoluções indicam as normas técnicas da ABNT: NBR $\mathbf{n}^{\mathbf{0}}$. 9.714/2000 (ABNT, 2000) - Ruído emitido por veículos automotores na condição parado - Método de ensaio no que se refere à medição de ruído nas proximidades do escapamento; e NBR $\mathrm{n}^{\circ}$. 8.433/1995 - Ruído emitido por veículos automotores em aceleração - Método de ensaio. Em 2002, esta norma, NBR n ${ }^{\circ} .8 .433$, foi cancelada e substituída pela ABNT NBR ISO $n^{\circ}$. 362/2002 - Medição do ruído emitido por veículos rodoviários automotores em aceleração - Método de engenharia. Entretanto, atualmente está em vigor a NBR $\mathbf{n}^{\mathbf{0}} \mathbf{. 1 5 . 1 4 5 / 2 0 0 4}$ (ABNT, 2004), que, por sua vez, cancelou e substitui a NBR ISO $n^{\circ}$. 362), recebendo a mesma denominação, ambas da ABNT. Ainda devem ser observadas alterações de limites para veículos com características especiais, conforme a Resolução CONAMA nº . 242/1998 (BRASIL, 1998a). 
Podem ainda ser identificadas outras três resoluções normativas quanto ao nível máximo de emissão sonora por veículos. Para os veículos com motor do ciclo Diesel tem-se a Resolução CONAMA nº. 007/1993 (BRASIL, 1993c); para motores destinados a veículos pesados novos, nacionais e importados, temos a Resolução CONAMA n ${ }^{\mathbf{0}}$. 008/1993 (BRASIL, 1993d); e, para os veículos rodoviários automotores, inclusive veículos encarroçados, complementados e modificados, nacionais ou importados, aplica-se a Resolução CONAMA nº . 252/1999 (BRASIL, 1999).

Em complemento, verifica-se a Resolução CONAMA nº 017/1995 (BRASIL, 1995) que ratifica os limites máximos de ruído e o cronograma para seu atendimento determinados pela Resolução CONAMA nº. 008/1993, acima apresentada; e a Resolução CONAMA no. 272/2000 (BRASIL, 2000), a qual estabelece novos limites máximos de ruído para veículos contemplados pela referida Resolução CONAMA ñ . 008/1993. Devem ainda ser observadas às resoluções CONAMA $\mathbf{n}^{\mathbf{0}}$. 020/1996 (BRASIL, 1996) e CONAMA n ${ }^{.230 / 1997 ~(B R A S I L, ~ 1997), ~ q u e ~ p r o i ́ b e m ~}$ o uso de equipamentos que possam reduzir a eficácia do controle de emissão de ruído, os denominados itens de ação indesejável.

Por último, grande destaque deve ser atribuído à recente Resolução do Conselho Nacional de Trânsito - CONTRAN nº. 204/2006 (BRASIL, 2006a), que regulamenta o art. 228 do Código de Trânsito Brasileiro - CTB quanto ao volume do funcionamento de aparelhos de som instalados em veículos, bem como os níveis toleráveis, a metodologia de avaliação e os casos em que se aplica, visto que se excetuam veículos com autorizações especiais.

O tráfego veicular intenso, apresentado em diversos estudos como uma das maiores fontes de ruído em centros urbanos, quando não, a principal, tem apontado relações diretas entre o inadequado ordenamento territorial, discutido anteriormente, e a não observância de parâmetros normativos estabelecidos nas resoluções apresentadas.

Complementarmente, medidas estruturais podem estar previstas nos objetivos da Política Municipal de Meio Ambiente, tais como: a localização adequada dos pólos geradores de tráfego rodoviário acentuado, principalmente o que ocorre no período noturno, a manutenção do bom estado de conservação dos pavimentos, entre outras ações decorrentes da engenharia de tráfego e secretaria municipal de obras.

Ainda entre as medidas estruturais, aplicáveis inclusive para áreas urbanas já consolidadas, sobretudo, em cidades onde as vias apresentam configurações indesejáveis, muito estreitas, por exemplo, caberia estabelecer a localização mais apropriada de equipamentos como semáforos, onde os veículos se acumulam em funcionamento, bem como a posição de lombadas, próximo às quais ocorre com maior freqüência, freadas e acelerações, devendo estes, entre outros fatores que intensificam o nível sonoro, como o duplo sentido de circulação, uso de buzinas e limites de velocidade maiores, estar distanciados de escolas, hospitais e demais zonas predominantemente compostas por estabelecimentos de natureza semelhante 


\section{(TROPPMAIR, 2002).}

Como conseqüência do desenvolvimento da cidade, o contínuo aumento da frota de veículos agrava ainda mais a emissão de ruídos. Na inviabilidade de corrigir problemas estruturais, ou mesmo complementar medidas dessa natureza, medidas não estruturais pautam-se fundamentalmente pelos dispositivos legais apresentados, que tornam juridicamente legítimas as ações necessárias, como uma adequada físcalização da emissão de ruído por veículos automotores, bem como do abusivo volume de aparelhos de som, nestes instalados.

Nesse sentido, medidas embasadas nos dispositivos legais apresentados também permitem coibir fatores relacionados às inúmeras características dos veículos barulhentos, entre elas: mau estado de conservação, com escapamentos furados ou enferrujados; motores desregulados por falta de manutenção ou ocasionados por alterações intencionais, como no silencioso ou no cano de descarga; e ainda, o uso de itens indesejáveis que prejudicam o controle do ruído associado a maus hábitos ao dirigir, como intensas acelerações, freadas bruscas e o uso excessivo de buzina; características, essas, apontadas por Machado (2004), como as principais causas de ruído veicular.

Quanto ao ruído aeronáutico, outro significativo componente da paisagem sonora no entorno de aeródromos, o Código Brasileiro de Aeronáutica, instituído pela Lei Federal $\mathbf{n}^{\mathbf{0}}$. 7.565/1986 (BRASIL, 1986), em seus arts. 43 e 44 dispõem sobre restrições especiais relativas ao uso das propriedades vizinhas dos aeródromos e das instalações de auxílio à navegação aérea, estabelecendo, quanto ao controle do impacto das emissões sonoras, o Plano de Zoneamento de Ruído.

Nesse sentido, o Decreto Federal $\mathbf{n}^{\mathbf{0}} \mathbf{. 8 9 . 4 3 1 / 1 9 8 4}$ (BRASIL, 1984) estabelece definições e normas relacionadas aos Planos Básicos e Específicos de Zoneamento de Ruído, a que se refere o Código Brasileiro do Ar (BRASIL, 1938), substituído pela referida Lei Federal $\mathrm{n}^{\mathrm{o}}$. 7.565/1986. Segundo o art. $3^{\circ}$ deste Decreto, as administrações públicas deverão compatibilizar seus diplomas legais e normativos referentes ao uso e ocupação das áreas abrangidas pelos sistemas aeroportuários conforme as restrições especiais definidas por estes Planos.

Segundo estudo realizado por Nunes e Sattler (2004), a Portaria $\mathbf{n}^{\mathbf{0}}$. 1.141/1987 do Ministério da Aeronáutica, define critérios para a determinação de duas curvas de nível de ruído, as quais limitam as zonas I, II e III, quanto às restrições de uso do solo, instituindo diferentes zonas de proteção das comunidades.

Os projetos de edificação dentro das zonas I e II devem ser submetidos ao Comando da Aeronáutica e atender, entre outros requisitos, as especificações da norma técnica da ABNT NBR no $\mathbf{8 . 5 7 2 / 1 9 8 4}$ (ABNT, 1984) - Fixação de valores de redução de nível de ruído para tratamento acústico de edificações expostas ao ruído aeronáutico, pois de acordo com o Decreto Federal no $n^{\circ}$ 89.431/1984, nestas áreas poderão ser liberados, pelos órgãos municipais competentes, determinados usos se atendidas tais exigências de tratamento acústico.

Por fim, visando atender ao interesse público, conforme o disposto no Decreto 
Federal $\mathbf{n}^{0}$. 5.731/2006 (BRASIL, 2006b), compete a ANAC - Agência Nacional de Aviação Civil regular e fiscalizar o ruído aeronáutico que, a partir do Decreto Federal $\mathbf{n}^{\mathbf{}}$. 5.745/2006 (BRASIL, 2006c), referente ao acordo entre o Brasil e os EUA, deverá observar a aprovação ambiental mediante o atendimento dos padrões, não apenas brasileiros, mas também, internacionais.

Entre os principais problemas relacionados ao tráfego aéreo está o ruído aeronáutico, representando a poluição que afeta o maior número de pessoas nas redondezas de aeroportos (ANDRADE, 2004).

Nesse contexto, as operações de pouso, decolagem e teste de motores estão entre as principais fontes de poluição sonora e devem ser devidamente gerenciadas para mitigar seus efeitos nocivos, buscando, por exemplo, alternar o uso de pistas e estudar os horários mais apropriados para as operações e testes das aeronaves.

Embora as áreas mais afetadas pelo ruído aeronáutico possam concentrar-se em locais ocupados irregularmente (zonas de proteção), isso não isenta a administração do aeroporto da responsabilidade de controlar os impactos decorrentes (CALDAS, 1993).

Como visto, o uso e ocupação do solo no sítio aeroportuário é regido, principalmente, pelo zoneamento das áreas expostas ao ruído aeronáutico. Todavia, recomenda-se a incorporação pelo poder público, em seus próprios dispositivos legais, de diretrizes que gerenciem a implantação e operação de aeroportos em seu município, visando um controle mais efetivo dos impactos sobre a população circunvizinha.

Logo, os dispositivos legais apresentados proporcionam ao poder público local instrumentos fundamentais para obrigar a implantação de medidas capazes de atenuar os impactos do ruído aeronáutico, fiscalizando a avaliação e certificação dos diversos fatores que implicam na poluição sonora decorrente, bem como exigir, para isso, que sejam atendidas todas as condições estabelecidas pelos termos de licenciamento ambiental da atividade.

\subsection{Sanções Ambientais}

Segundo o Decreto-Lei Federal $\mathbf{n}^{\mathbf{0}}$. 3.688/1941 (BRASIL, 1941), denominado Lei das Contravenções Penais, condutas e/ou atividades ruidosas caracterizam contravenção referente à paz pública, e em seu art.42 resolve:

Art. 42. Perturbar alguém, o trabalho ou sossego alheios:

I - com gritaria ou algazarra;

II - exercendo profissão incômoda ou ruidosa, em desacordo com as prescrições legais;

III - abusando de instrumentos sonoros ou sinais acústicos;

IV - provocando ou não procurando impedir barulho produzido por animal de que tem guarda:

Pena - Prisão simples de quinze dias a três meses, ou multa.

Observa-se, portanto, que desde então a Lei já amparava a sociedade contra os 
efeitos da Poluição Sonora, muito antes mesmo de se pensar na questão ambiental de forma mais ampla, tal como é abordada atualmente (PEREIRA-JR, 2002).

Mais recentemente, ao dispor sobre medidas repressivas aos que comprometerem a qualidade ambiental e não cumprirem as ações necessárias à correção dos inconvenientes e danos causados, a Lei Federal $\mathbf{n}^{\mathbf{0}} \mathbf{. 6 . 9 3 8 / 1 9 8 1}$, ainda prevê a tais transgressores penas pecuniárias, restritivas de direito, indenização ou reparo a danos causados e, até mesmo, suspensão da atividade.

Contudo, embora a Lei Federal no $\mathbf{9 . 6 0 5 / 1 9 9 8 ~ ( B R A S I L , ~ 1 9 9 8 b ) , ~ d e n o m i n a d a ~}$ Lei dos Crimes Ambientais, que dispõe sobre as sanções penais e administrativas derivadas de condutas e atividades lesivas ao meio ambiente, tenha chegado a explicitar a Poluição Sonora entre os crimes ambientais em seu art. 59:

Art. 59. Produzir sons, ruídos ou vibrações em desacordo com as prescrições legais ou regulamentares, ou desrespeitando as normas sobre emissão e imissão de ruídos e vibrações resultantes de quaisquer atividades: detenção, de três meses a um ano, e multa.

este dispositivo foi vetado sob a justificativa de que a redação do art. 42 do DecretoLei Federal $n^{\circ}$. 3.688/1941 já tipificaria a perturbação do trabalho ou do sossego alheio, tutelando juridicamente a qualidade ambiental de forma mais apropriada e abrangente.

Anterior à Resolução CONTRAN no. 204/2006, o volume excessivo de aparelhos de som em veículos também era tipificado como contravenção penal, entretanto, com o advento desse novo dispositivo, passou a ser definida como infração de trânsito, de natureza grave, tal como estabelece o art. 228 do CTB, equivalente ao acréscimo de 5 pontos na Carteira Nacional de Habilitação e multa de 120 UFIR (arts. 258 e 259 do CTB):

Art. 228. Usar no veículo equipamento com som em volume ou freqüência que não sejam autorizados pelo CONTRAN: Infração - grave; Penalidade - multa; e Medida administrativa - retenção do veículo para regularização.

Por último, ainda pode ser destacado o art. 59 do Decreto Federal $\mathbf{n}^{\mathbf{0}}$. 6.514/2008 (BRASIL, 1999), que estabelece pena pecuniária aos fabricantes que não garantirem o atendimento dos limites sonoros exigidos pela legislação vigente, bem como deixar de fornecer aos usuários todas as orientações sobre a correta utilização e manutenção de veículos ou motores.

É cediço que ninguém tem o direito adquirido de poluir, entretanto, a efetividade das soluções legislativas passa fundamentalmente pelo seu cumprimento, caso contrário, tornam-se ocultas, desencadeando a má conduta da sociedade e omissão da gestão pública local. Nesse sentido, são necessários mecanismos que obriguem o atendimento da legislação, sendo esta, muitas vezes, a única alternativa capaz de contornar lacunas estabelecidas pela ausência de programas eficientes de conscientização. 
Portanto, as leis abordadas no conjunto das sanções ambientais aplicáveis a poluição sonora, proporcionam ao poder público local recursos administrativos e, quando for o caso, subsídios para encaminhar a instauração de processos civis ou penais, visando, sobretudo, coibir infrações com a conseqüente mudança de conduta, fundamental para o tratamento dos problemas relacionados aos ruídos urbanos.

\section{CONSIDERAÇÕES FINAIS}

Fundamentando-se na abordagem apresentada, não se pode concluir que as diretrizes federais aplicáveis ao controle da poluição sonora não têm avançado, pois com o presente estudo descortinou-se vasta legislação abrangente, contemplando suas principais causas.

Entretanto, ratificam-se as suspeitas quanto à dispersão dos dispositivos legais e a conseqüente valia em unificar tais diretrizes com a sistemática aqui aplicada, subsidiando, dessa forma, a consolidação de tais dispositivos por contribuir para a sua divulgação, compreensão e, consequentemente, aplicabilidade.

Ressalte-se ainda que o efetivo controle da poluição sonora fica a encargo do Poder Público Municipal que, para isso, embasado nas premissas legais apresentadas, pode avançar em seu próprio instrumental jurídico, bem como atuar com mais rigor em seu poder de polícia e em políticas alinhadas a um pleno e equilibrado plano de desenvolvimento urbano.

Todavia, não podemos olvidar que a efetividade da legislação ora apresentada, e da própria atuação dos gestores municipais, agentes privados e órgãos ambientais, também se compromete na ausência de recursos humanos qualificados e condições operacionais adequadas, contribuindo para o crescente aumento da poluição sonora observado atualmente.

Por fim, aliado a outros mecanismos que devem ser investigados para o tratamento em nível local desta problemática, acredita-se que o presente trabalho pode contribuir significativamente com a gestão do ruído urbano, pois objetiva orientar mudanças que visem melhorar a qualidade de vida, apresentando soluções jurídicas aplicáveis ao controle e prevenção de um entre os principais agravantes da vida moderna, a poluição sonora.

\section{REFERÊNCIAS}

ASSOCIAÇÃO BRASILEIRA DE NORMAS TÉCNICAS (ABNT). NBR 7.731. Guia para execução de serviços de medição de ruído aéreo e avaliação de seus efeitos sobre o homem. Rio de Janeiro, 1983. 11p.

. NBR 8.572. Fixação de valores de redução de nível de ruído para tratamento 
acústico de edificações expostas ao ruído aeronáutico. Rio de Janeiro, 1984. 8 p.

. NBR 10.152. Avaliação do ruído ambiente em recintos de edificações visando o conforto dos usuários. Rio de Janeiro, 1987. 5p.

. NBR 10.151. Avaliação do ruído em áreas habitadas visando o conforto da comunidade. Rio de Janeiro, 2000. 4p.

. NBR 9.714. Ruído emitido por veículos automotores na condição parado. Rio de Janeiro, 2000. 8p.

. NBR 15.145. Errata. Rio de Janeiro, 2003. 01p.

. NBR 15.145. Medição do ruído emitido por veículos rodoviários automotores em aceleração. Rio de Janeiro, 2004. 13p.

ANDRADA, B. Consolidação da Legislação Ambiental Brasileira. Brasília, 03 set. 1997. Disponível em: < www.ambientebrasil.com.br/images/noticias/clab.pdf >. Acesso em: 15 out. 2005.

ANDRADE, F. Gerenciamento dos Impactos Ambientais no Aeroporto Internacional de São Paulo. Guarulhos, 2004. Disponível em: $<$ http://www2.ita.br>. Acesso em: 19 nov. 2005.

BRASIL. Constituição. 1988. Constituiçãa: República Federativa do Brasil. São Paulo: LTr, 1988. 292 p.

Decreto-Lei Federal $\mathbf{n}^{\mathbf{0}}$. 3.688. 1941. Lei das contravenções Penais. Disponível em: < http://www.planalto.gov.br/ccivil/decreto-lei/del3688.htm>. Acesso em: 05 dez. 2006.

. Lei Federal $\mathbf{n}^{\mathbf{0}}$. 6.803. 1980. Dispõe sobre as diretrizes básicas para o zoneamento industrial. Disponível em: < http://www.planalto.gov.br/ccivil_03/leis/ 16803.htm>. Acesso em: 05 dez. 2006.

. Lei Federal no . 6.938. 1981. Dispõe sobre Política Nacional do Meio Ambiente. Disponível em: < www.planalto.gov.br/ccivil_03/leis/L6938.htm >. Acesso em: 05 dez. 2006.

. Decreto Federal nº. 89.431. 1984. Dispõe sobre o Plano Básico de Zoneamento de Ruído. Disponível em: < www.planalto.gov.br >. Acesso em: 05 dez. 2006. 
. Lei Federal nº 7.565. 1986. Código Brasileiro de Aeronáutica. Disponível em: < www.planalto.gov.br/ccivil_03/Leis/L7565.htm >. Acesso em: 05 dez. 2006.

. Resolução Conama nº 001. 1986. Dispõe sobre a avaliação de impacto ambiental. Disponível em: < www.mma.gov.br/port/conama/res/res86/res0186.html >. Acesso em: 05 dez. 2006.

. Resolução Conama no . 001. 1990a. Dispõe sobre o controle da poluição sonora. Disponível em: < www.mma.gov.br/port/conama/res/res90/res0190.html >. Acesso em: 05 dez. 2006.

. Resolução Conama no . 002. 1990b. Dispõe sobre a Política Nacional de Educação e Controle da Poluição Sonora. Disponível em: < www.mma.gov.br/port /conama/res/res90/res0290.html >. Acesso em: 05 dez. 2006.

. Resolução Conama nº 001. 1993a. Dispõe sobre a emissão de ruído veicular. Disponível em: < www.mma.gov.br/port /conama/res/res92/res0192.html >. Acesso em: 05 dez. 2006.

. Resolução Conama no . 002. 1993b. Dispõe sobre a emissão de ruído veicular. Disponível em: < www.mma.gov.br/port/conama/res/res92/res0292.html >. Acesso em: 05 dez. 2006.

. Resolução Conama no . 007. 1993c. Dispõe sobre a emissão de poluentes por veículos automotores. Disponível em: < www.mma.gov.br/port/conama/res/res93/ res0793.html >. Acesso em: 05 dez. 2006.

. Resolução Conama n⿳0.008. 1993d. Dispõe sobre a emissão de poluentes por veículos automotores. Disponível em: < www.mma.gov.br/port/conama/res/res93/ res0893.html >. Acesso em: 05 dez. 2006.

. Resolução Conama no $\mathbf{n}^{0}$ 020. 1994. Instituí o selo ruído. Disponível em: < http://www.mma.gov.br/port/conama/legiabre.cfm?codlegi=161 >. Acesso em: 05 dez. 2006.

. Resolução Conama nº 017. 1995. Ratifica disposições sobre a emissão de ruído veicular. Disponível em: < www.mma.gov.br/port/conama/res/res95/res1795.html >. Acesso em: 05 dez. 2006.

. Resolução Conama no . 020. 1996. Define os itens de ação indesejável, referente à emissão de ruídos. Disponível em: < 
http://www.ibama.gov.br/licenciamento/modulos/arquivo.php?cod_arqweb=con02096 >. Acesso em: 05 dez. 2006.

. Lei Federal nº 9.503. 1997. Institui o Código de Trânsito Brasileiro.

Disponível em: < www.planalto.gov.br/ccivil/leis/L9503.htm >. Acesso em: 05 dez. 2006.

. Resolução Conama no ${ }^{.230 .}$ 1997. Proíbe uso de itens de ação indesejável. Disponível em: < www.mma.gov.br/port/conama/res/res97/res23097.html >. Acesso em: 05 dez. 2006.

. Resolução Conama no . 242. 1998a. Regulamenta disposições sobre a emissão de poluentes por veículos automotores. Disponível em: < www.mma.gov.br/port/ conama/res/res98/res24298.html >. Acesso em: 05 dez. 2006.

. Lei Federal $n^{0}$. 9.605. 1998b. Dispõe sobre sanções contra crimes ambientais. Disponível em: < www.planalto.gov.br/ccivil/leis/L9605.htm >. Acesso em: 05 dez. 2006.

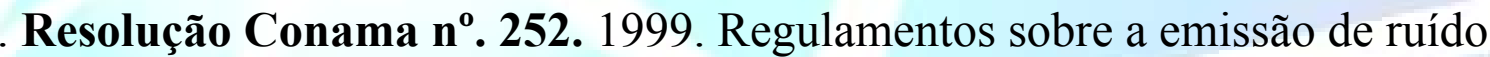
veicular automotor. Disponível em: < www.mma.gov.br/port/conama/res /res99/res25299.html >. Acesso em: 05 dez. 2006.

. Resolução Conama no . 272. 2000. Regulamentos sobre a emissão de ruído veicular automotor. Disponível em: < www.mma.gov.br/port/conama/res /res00/res27200.html >. Acesso em: 05 dez. 2006.

. Lei Federal $\mathbf{n}^{\mathbf{0}}$. 10.257. 2001. Estatuto da Cidade. Disponível em: $<$ http://www.planalto.gov.br/CCIVIL/Leis/LEIS_2001/L10257.htm >. Acesso em: 05 dez. 2006.

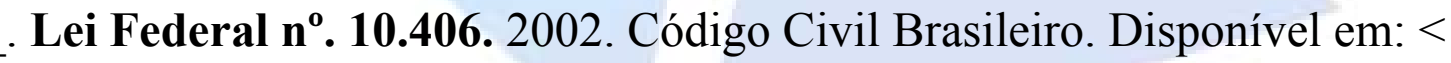
http://www.planalto.gov.br/CCIVIL/leis/2002/L10406.htm >. Acesso em: 05 dez. 2006.

Decreto Federal $\mathbf{n}^{0}$. 5.731. 2006a. Dispões sobre a Agência Nacional de Aviação Civil. Disponível em: < http://www.planalto.gov.br/ccivil_03/_Ato20042006/2006/Decreto/D5731.htm >. Acesso em: 05 dez. 2006.

. Decreto Federal $\mathbf{n}^{0}$. 5.745. 2006b. Promulga acordo relativo a aviação civil entre Brasil e o Estados Unidos. Disponível em: < http://www.planalto.gov.br /ccivil_03/_Ato2004-2006/2006/Decreto/D5745.htm >. Acesso em: 05 dez. 2006. 
. Resolução Contran no. 2.004 de 2006. Disponível em: $<$ http://

www.denatran.gov.br/download/Resolucoes Resolucao204_06.pdf >. Acesso em: 11 nov. 2006.

. Decreto Federal $\mathbf{n}^{\mathbf{0}}$. 6.514. 2008. Dispõe sobre as infrações e sanções administrativas ao meio ambiente. Disponível em: $<$ http://www.planalto.gov.br /ccivil_03/_Ato2007-2010/2008/Decreto/D6514.htm\#art153 >. Acesso em: 05 dez. 2006.

CALDAS, T. C. M. O Impacto dos Aeroportos no Meio Urbano: Uma análise das possibilidades de gerenciamento. Rio de Janeiro: UFRJ, 1993. 88 f. Dissertação (Mestrado em Planejamento Urbano e Regional). Universidade Federal do Rio de Janeiro, 1993.

FERNANDES, J. C. Acústica e ruídos: apostila. Bauru: UNESP, 2002. 98 p. Universidade Estadual Paulista, 2002. Disponível em: $<$ http://wwwp.feb.unesp.br/jcandido/acustica/ apostila.htm>. Acesso em: 15 jan. 2007.

MACHADO, A. A. Poluição sonora como crime ambiental. Jus Navigandi, Teresina, n. 327, p. 01-16, mai. 2004. Disponível em: < http://jus2.uol.com.br/doutrina /texto.asp?id=5261 >. Acesso em: 1 out. 2005.

MILARÉ, E. Direito Ambiental: doutrina, prática, jurisprudência e glossário. $2^{\mathrm{a}}$ Ed. rev. atual. e ampl. São Paulo: Revista dos Tribunais, 2001. 783p.

NUNES, M. F. O.; SATTLER, M. A. Percepção ao ruído aeronáutico em escolas da Zona I do PEZR do Aeroporto Internacional Salgado Filho. ENGEVISTA, v. 6, n. 3, p. 05-24, dez. 2004.

OMS - ORGANIZAÇÃO MUNDIAL DA SAÚDE. Résumé D’orientation Des Directives De I'oms Relatives Au Bruit Dans I'environmental..2003. Disponível em: < http://www.who.int/home.page/ >. Acesso em: 5 mar. 2003.

PEREIRA-JR, J. P. Legislação federal sobre Poluição Sonora. Brasília, 2002. Disponível em: < http://acd.ufrj.br/consumo/vidaurbana/notatecnica_legislacao.pdf >. Acesso em: 12 out. 2005.

PINHEIRO PEDRO ADVOGADOS. Princípio de direito ambiental. Disponível em:

$<$ http://www.pinheiropedro.com.br/biblioteca/artigos_publicacoes/temas_ambientais/ 13_principio_direito_ambiental.php>. Acesso em: 13 jun. 2005. 
SÃO PAUlO (ESTADO). Secretaria de Estado do Meio Ambiente. Política municipal do meio ambiente. $2^{\mathrm{a}}$ ed. São Paulo: Fundação Prefeito Faria Lima, 1992. $167 \mathrm{p}$.

TROPPMAIR, H. Poluição sonora na área central do espaço urbano de Rio Claro. Boletim de Geografia Teorética. AGETEO. Rio Claro, v. 27, n. 1, p. 83-94, abril 2002. 